Article

\title{
Project-Based Market Competition and Policy Implications for Sustainable Developments in Building and Construction Sectors
}

\author{
Min-Ren Yan \\ Department of International Business Administration, Chinese Culture University, No. 231, Sec. 2, \\ Jian-guo S. Rd., Da-an Dist., 106 Taipei City, Taiwan; E-Mail: mjyen@sce.pccu.edu.tw; \\ Tel./Fax: +886-2-2700-5858 (ext. 8672)
}

Academic Editor: Yongrok Choi

Received: 16 October 2015 / Accepted: 13 November 2015 / Published: 20 November 2015

\begin{abstract}
Building and construction sectors are significant contributors to the global economy, but their energy consumption necessitates greater commitment to sustainable developments. There is therefore a growing demand for green innovation in the form of cleaner production and policies to meet the modern requirements of sustainability. However, the nature in which public work is undertaken is in an environment of project-based market competition, whereby contractors routinely bid for contracts under specific project awarding systems, and variations are accompanied with the unique scope of individual projects before the final goods or services are delivered. A comprehensive understanding of the characteristics and contractors' behavior in systems could help to identify the leverage points of policies. This paper proposes a system dynamics model, with quantitative analysis and simulations, to demonstrate the problems of a system with different project awarding systems and ineffective market performance. The framework of market efficiency and performance measures has been proposed to evaluate the project-based competition mechanism. Managerial policy implications for market efficiency and sustainable developments can thus be systematically discussed and compared through iterative computer simulations and scenario analysis.
\end{abstract}

Keywords: project awarding; procurement; opportunistic bidding; contractor selection; competition; system dynamics; sustainability; sustainable development; policy 


\section{Introduction}

Throughout history, the building and construction sectors have long been acknowledged as holding a unique position in contributing to economic development and quality of living improvements around the world. Although previous studies estimated that construction can contribute approximately $13 \%$ of the global gross domestic product (GDP) [1], this comes as a cost, since various statistics show excessive consumption of global resources and excessive energy use and associated global greenhouse gas (GHG) emissions [2,3]. The building sector accounts for $30 \%-40 \%$ of global energy use by the United Nations Environment Program [4]. Spence and Mulligan [5] reported that the construction of buildings annually consumes $25 \%$ of virgin wood and $40 \%$ of raw stone, gravel and sand. In addition, globally, buildings could consume $16 \%$ of the water and indirectly produce nearly $70 \%$ of all sulfur oxides [6]. The pressures of sustainable development in the building and construction sectors have become an emerging issue across the world and include the improvement of construction practices and green innovations, such as ecological construction, green building, recycling and eco building materials, in order to minimize their environmental impacts [7-13]. However, the building and construction industries have been blamed for issues in technological innovations, quality and sustainability with inadequate market competition and governmental policies. More comprehensive standards and governmental policies that lead to a positive market environment are critical for sustainable developments in the building and construction sectors.

This need for more sustainable products, design and construction processes has been noticed by international organizations and governmental policies that now promote new standards for sustainability in building and construction industries, including the requirements for functional, technical, environmental, social and economic performances [14]. Many efforts and standards have been implemented to enhance the environmental sustainability of the construction process at different management levels; for example, the U.S. Green Building Council (USGBC)'s Leadership in Energy and Environmental Design (LEED) green building rating system, ISO 14001 certification and European CEN/TC350 (sustainability of construction works) [14,15].

With increasing awareness of policies for sustainability in the building and construction sectors, considerable effort has focused on environmental performance and consumption of construction processes and the operation of buildings and infrastructures [15]. However, few studies have dealt with governmental procurement policies, the project-based market competition mechanism and their impacts on sustainable development. Sustainability is a complex concept in the building and construction industries, and there are many diverse stakeholders that may contribute to the success or failure of sustainability measures, including government agencies, clients, general contractors and the professional sub-contractors [16]. Previous studies have proposed that the transformation of sustainable construction to less energy consumption and associated air emissions is at a relatively early stage because of the decentralized nature of construction processes and the fragmented subcontracting system [15]. Some construction companies are trying to overcome environmental pressures by seeking technological innovations that provide specific advantages for clean construction [17]. Factors such as public regulatory changes and market mechanisms need to facilitate the improvements of sustainable developments in the building and construction industries, even though the industry has an enormous reputation for being conservative with respect to change [18-20]. 
To facilitate contractors' upgrades and green innovations, a systematic understanding of project-based competition characteristics and governmental policy implications is needed. Government agencies regularly procure construction projects, service projects or equipment through specific project awarding systems. For decades, the price-based system (PBS) has been extensively used for project awarding. In a price-based awarding system (or the lowest price bidding system), contractors are invited openly to submit sealed prices individually, and the contractor who offers the lowest price for the project will be awarded. The PBS is especially popular for government-procured projects. Governments utilize this system for its simplicity and fairness and expect to obtain economic benefit through price competition [21,22]. However, as many unreasonable price competitions and consequent poor project performance have been frequently observed, many researchers have pointed out that the price competition itself is not sufficient to guarantee an economical and quality product [23]. Accordingly, the qualification-based system (QBS) has been proposed as an alternative to find competent contractors, while considering more non-price criteria for project awarding (alternatively, this could be regarded as the best value system) [23,24].

Since the project owner is the only buyer in the market, the project awarding system adopted by the project owner would form the rules of competition and market competitive behavior. From the perspective of industrial economics S-C-P (structure-conduct-performance) theory, the rules of market competition and contractor's competitive behavior would determine the outcomes of contractors' performance and the development of the whole industry. This is especially true when the pressures on sustainability continuously call for improvements in the built environment and its operations. However, previous studies have mostly concerned the contractor selection and project awarding from the project-level viewpoint. From the industry-level viewpoint, few studies have developed models to analyze the project-based market competition, market efficiency and managerial policies under the price-based and qualification-based awarding systems. To fill the gap, this paper aims to propose a system dynamics model that demonstrates the market competitive behavior and the inherent system problems of ineffective competition under PBS and QBS. The unique contributions of this paper are specifically delivered with qualitative systems analysis and simulation-based quantitative analysis. For qualitative analysis, a set of contractors' behavioral systems inherent in the project-based transaction process is explored from a holistic perspective. For the quantitative analysis, a simulation model is proposed as an explanatory model for evaluating the dynamics of competition and market efficiency under different managerial policies. The proposed models can help researchers and practitioners better understand the project-based market competition and evaluate managerial policies that promote sustainable developments in the building and construction sectors.

\section{Research Methodology}

System dynamics (SD) was the main methodology adopted in this paper. The methodology was first proposed in 1956 by MIT professor Jay Forrester with a foundation of decision-making, dynamic relationships, feedback analysis and simulation [25]. In the past few decades, SD has been comprehensively used to analyze many complex social systems, particularly in industrial contexts [26]. SD emphasizes how the focus of the study interacts with the other constituents of the system. SD modeling efforts can improve our understanding of the relationships between feedback structures 
and the dynamic behaviors of a system, so that policies for improving problematic behavior may be developed. The concept is consistent with agent-based computational economics (ACE), the emerging science in the economics field, which emphasizes the modeling economic process as a dynamic complex system [27]. By "stock-flow" modeling, SD emphasizes the evaluations of quantified performance over time for the research subjects and derives model-based understanding and applicable policy insights from the simulation-based scenario analysis. Thus, the SD modeling in this paper can support the analysis of market competitive behavior from a holistic viewpoint. It also functions as a virtual laboratory for policy experiments, which are generally difficult using traditional analytic tools.

Although there is no single standardized process for the implementation of the SD model and validation, methodologically, this research was conducted by three major processes: (1) system conceptualization; (2) model formation and validation; and (3) scenario analysis and policy evaluation. First, after the identification of research objectives, a literature review was conducted to explore the issues of abnormal low bids, poor quality and contractors' opportunistic bidding behavior under project-based market competition. System conceptualization means that the system is described in a qualitative language to show the dynamics of the variables involved in the observed systems. The result of the conceptualization is represented in the form of a causal loop diagram, which serves as a primitive form of the proposed SD model. Accordingly, this paper uses causal loop diagrams to depict contractors' behavioral feedback loops under price-based and qualification-based awarding systems. Second, in the model formation and validation step, the developed causal loop diagrams evolved to have quantitative attributes. By providing numbers and equations for the diagrams, a simulation model was developed that required proper testing or validation. This paper integrated the modules of simulation models in previous studies with modified measures for extended applications. The modules were verified by the partial model testing method, sensitivity analysis and mathematical checking. Finally, for scenario analysis and policy evaluation, iterative simulations were performed to analyze the circumstances under different project awarding systems and market scenarios. The impacts of different managerial policies on improving market efficiency and ideal performance were also evaluated.

Previous studies have indicated that the only statements that can be validated are pure analytic statements; thus, an SD model developed to mimic social systems cannot be verified [28]. Alternatively, SD model testing focuses on the iterative process to build confidence that a model is appropriate for the research purpose. A wide range of specific tests have been developed to uncover flaws and improve models in the SD field. Besides the testing methods for correcting mathematical errors, model testing methods can be grouped into two types in terms of the purpose of the testing. The first type of model testing is for assuring the accuracy or the predictability of the developed model, and the second one is for assuring the logic of rules in the developed model. The first type of testing is particularly applicable when a model is developed for predictions or for determining sophisticated quantities; for example, a model developed for predicting the sale ratio of housing projects or for selecting a profitable plan for housing projects. In this situation, modelers usually need abundant historical data to estimate the precise magnitude of each variable, so as to assure the accuracy of the model. As the proposed SD model in this paper is not used to calculate contractors' bidding prices and exact market prices, but only used to simulate how specific competitive behaviors affect the market efficiency by controlling variables, the logic of rules adopted in the model should be the focus of model testing. Therefore, this paper adopted the principles of the partial model test [28]. 
In a partial model test, the function or variable of interest is controlled in an exclusive environment independent of the interactions or influences from the other variables or functions, to test its intended rationality. For instance, each loop in a three feedback loop system can be analyzed independently when the other two loops are temporarily excluded and deemed as exogenous to the system. After each component of a complicated system passes the logical checking of partial model tests, the reliability of the model is further enhanced. Therefore, throughout the following sections, this paper firstly explains the logics of ideas, as well as the systems analysis of the project-based market competition with causal loop diagrams. Then, an integrated simulation model with structural equations and parameter settings from previous studies were carefully adopted. Scenario analysis and sensitivity analysis with different parameter settings were performed for policy evaluation.

\section{Systems Analysis of the Project-Based Market Competition}

In this section, the market competitive behavior under the price-based and qualification-based awarding system is analyzed from a systems thinking perspective adopting the causal loop diagram and the concept of reinforcing and balancing feedback loops. The reinforcing feedback loop represents the effects of malign or benign cycles, and a balancing feedback loop symbolizes the tendency to maintain a goal.

\subsection{The Market Competitive Behavior under the Price-Based Awarding System}

The basic principle behind the PBS is that the price competition process encourages efficiency and innovations by contractors. Under an ideal market mechanism, contractors can benefit from the use of innovative production technologies to reduce costs, encouraging the growth of the contractors, even though quality improvement involves a learning process over time [29]. For public agencies, PBS will also protect the public from extravagance, corruption and other improper practices by public officials. Previous studies have developed a holistic model to demonstrate the benefits and concerns of the PBS in the construction industry [30]. Since the building and construction industry is representative of markets by project-based competition, the findings could be adopted for the model developments in this paper.

Based on the Bertrand price competition model of economics, companies will assess and predict prices offered by their competitors before they determine their own price [31]. Accordingly, the bidding prices of previous tenders (market price) are important references for bidders of subsequent tenders and have feedback relationships with contractors' bidding prices. The previous bidding prices sequentially affect contractors' pricing in the subsequent tenders, while contractors are forced to lower their prices in response to price competition.

On the other hand, previous studies have also suggested that an identical causal relationship exists between market price and the number of competitors [32,33]. A higher market price will attract more competitors, but these competitors have to steeply cut prices to win contracts in the competitive market. Consequently, the market price might dramatically drop down and force some competitors to quit the market. This balancing feedback process depicts a company's behavior in response to the demand and supply relationship until both the market price and the number of competitors are balanced.

In this section, this paper highlights contractors' opportunistic bidding behavior as an inherent system problem of the PBS with behavioral feedback loops. Lo et al. [34] proposed that contractors will 
opportunistically cut the bidding price to take a greater market share when they have an expectation of obtaining beyond-contractual rewards. The beyond-contractual reward (BCR) is defined as the cost reductions through cutting corners and the compensations gained from claims. In accordance with the aforementioned evidences, at least six adverse feedback loops hidden within the PBS have been identified [35]. Subsequent studies and empirical analyses support the adverse impacts on the building and construction industries in many countries, including the U.S. and China [36-41]. The structural feedback loops of project-based competition (as shown in Figure 1) are summarized as the following three groups:

(1) The feedback loops driven by opportunism:

The concept of opportunism represents that companies always want more of what they like, and this may imply that interests are pursued in an opportunistic fashion [42]. Accordingly, it is inferred that when contractors have experienced obtaining BCR in the past, they tend to repeatedly cut corners and abnormally raise claims to maximize profit, regardless of the reasonableness of the award price. The behavioral tendency would induce reinforcing feedback loops and adverse effects.

(2) The feedback loops driven by the pressures of competition:

When a contractor deliberately cuts a price, the cost pressure will induce the contractor to cut corners and abnormally raise claims in the project execution phase for survival. After a period of time and the experience accumulated, the contractor may have confident expectations of BCR and offer lower prices for future projects. This reinforcing feedback process will constantly intensify contractors' opportunism and the adverse effects.

(3) The feedback loops driven by pursuing BCR:

Rooke et al. [43] proposed that opportunistic contractors tend to expend more effort generating profit from claims instead of obtaining profit with improved construction methods. Accordingly, if there is potential BCR that is readily attainable, the opportunism will discourage contractors' willingness to improve their capabilities, especially when the award price is quite low and most contractors survive upon BCR. Previous economic studies have proposed that R\&D is engaged in improving the quality of products when product market competition gets more intense [44-47]. Bucci and Parello [48] found that the shape of the relationship between competition and growth can change dramatically according to which proxy of competition is used. However, the findings are not well applicable when contractors continuously pursue BCR as adverse feedback loops.

As contractors' opportunistic bidding behavior forms the aforementioned adverse feedback loops, which will continuously intensify over time, it can seriously damage the ideal functions of the PBS. In this situation, green innovations become relatively less important, and contractors are less incentivized to invest in research and development for sustainability. 


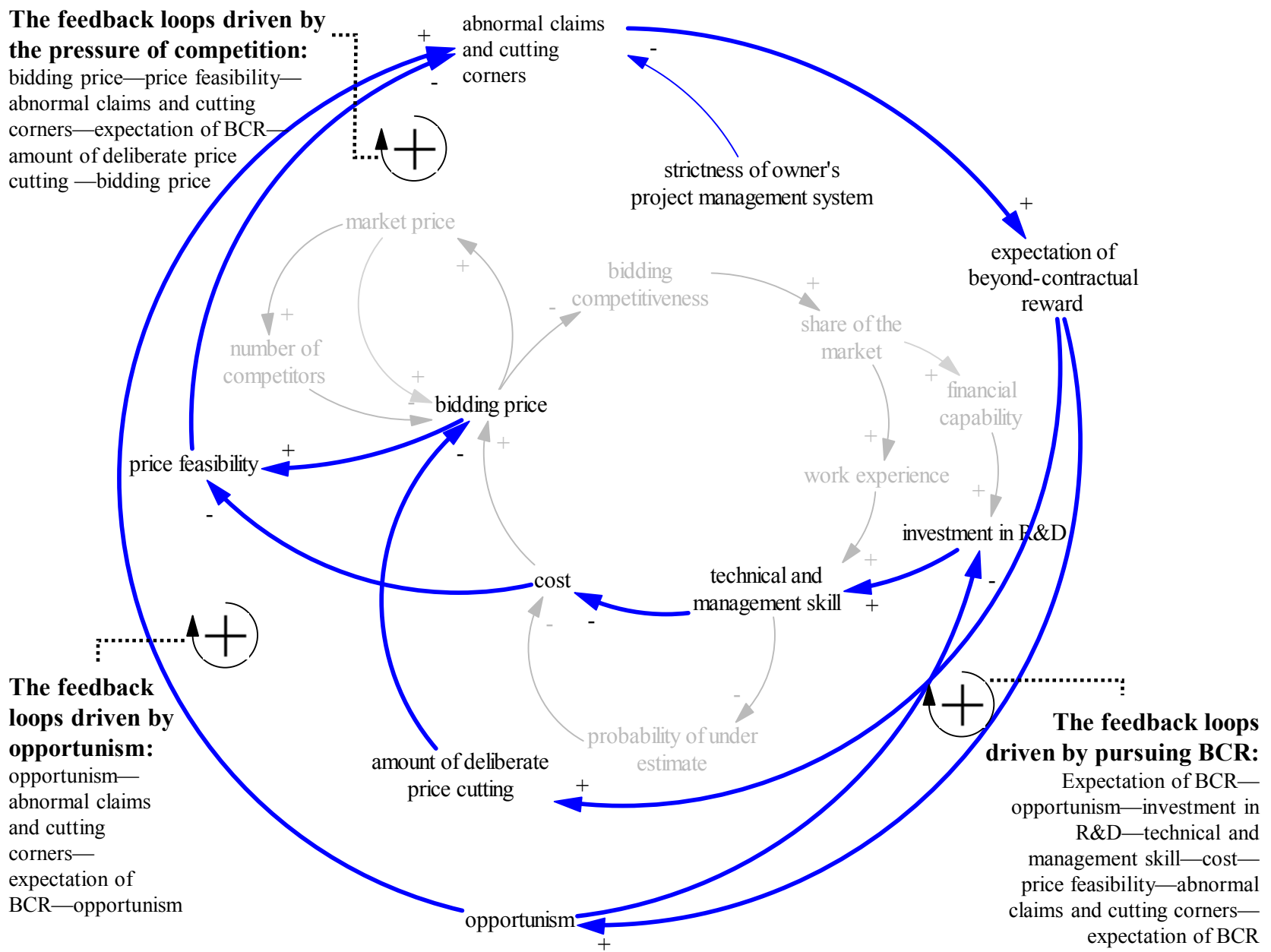

Figure 1. Firms' behavioral feedback loops under the price-based awarding system. BCR, beyond-contractual reward.

\subsection{Policy Implications for the Price-Based Awarding System}

The feedback loops analysis indicated that contractors' expectation of BCR can intensify their opportunism and the opportunistic bidding behavior, while the potential BCR in a project management system is a driving factor. Therefore, the owners have a strong incentive to put greater efforts into improving their project management system, including the soundness of contracts and the strictness of the monitoring system. A sound contract should include comprehensive documentation, specifications and drawings. Once the strictness of the owner's project management system is improved, the adverse loops may be obsolete. This policy is specifically important for the implementation of a sole PBS. Note that there are other types of projects, such as collaborative project arrangements, contractor-owner partnering contracts and strategic alliance projects, that might be affected by other critical factors outside the identified feedback loops.

\subsection{The Market Competitive Behavior under the Qualification-Based System}

To meet clients' multidimensional demands, such as time, cost, quality, environmental performance and sustainability, only one or two criteria might not be sufficient to identify a qualified contractor $[49,50]$. 
The QBS is designed to find qualified and competent contractors instead of lowest bidders. Besides price, non-price criteria, such as contractors' past performance, work experience, technical and management skills, financial capability, etc., are adopted in the system. The QBS can also be recognized as the "best value" selection system, while some studies distinguish best value selection and the QBS on whether the price is included or not in the project awarding criteria [51,52]. From the systems perspective, the use of the QBS will lead contractors to form additional reinforcing feedback loops (as shown in Figure 2).

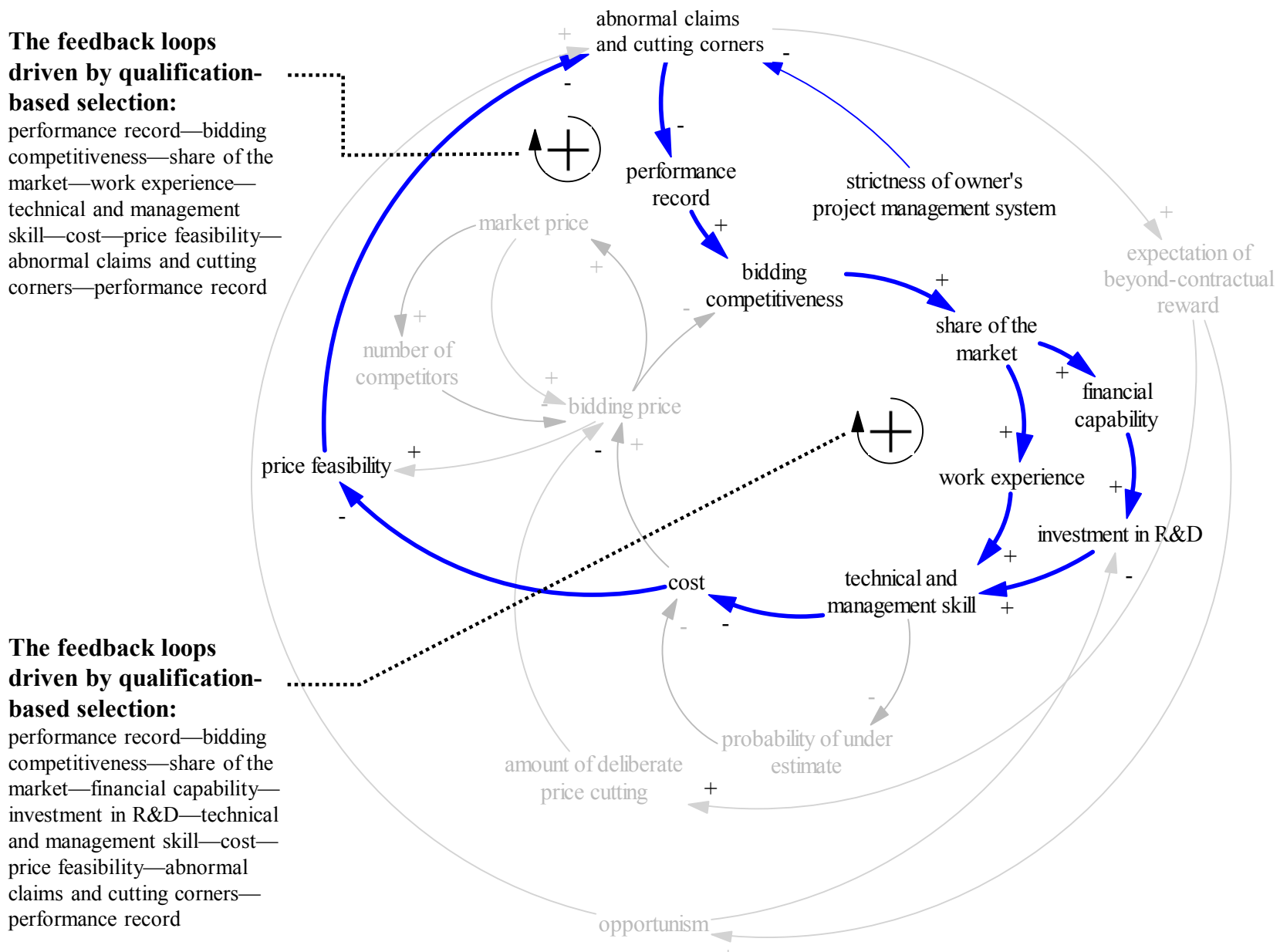

Figure 2. Firms' behavioral feedback loops under the qualification-based awarding system.

The inclusion of non-price criteria generates reinforcing loops, which lead contractors to increase competitiveness and expand their businesses in a positive way. An experienced contractor can gain more competitiveness in the selection phase and consequently obtain more share of the market and more work experience. In addition, QBS usually requires contractors to submit a technical proposal and brief on a project plan, management systems, equipment and technology, and other resources will be adopted. By taking construction projects as examples, contractors can create their competitiveness through innovative designs, materials and construction methods, so as to raise the project quality and better satisfy the owners' need [53]. Accordingly, reputable contractors with better technical and management skills will more likely be able to prepare quality proposals and win contracts. Green innovations and better proposals for sustainability would be acknowledged, especially for the building and construction 
projects that require higher ecological and environmental standards. Consequently, they have a greater chance to further improve technical and management skills through the execution of works and R\&D. In addition, when contractors' financial capability is considered in a QBS, a contractor with good financial capability will have greater competitive advantage and market share, enabling the contractor to further enhance his financial capability.

Lo and Yan [24] have suggested that the success of the QBS is highly dependent on the linkage between contractors' past performance and the evaluation of contractors' qualifications. Once a contractor's past performance becomes an important criterion to evaluate a contractor's qualification, contractors are forced to minimize corner cutting behavior and unreasonable claims, so as to maintain their performance record and competitiveness. This behavioral tendency forms reinforcing feedback loops, which provide contractors with an incentive to respect their performance in the project execution phase [35].

\subsection{Policy Implications for the Qualification-Based Awarding System}

Different from the situation in the PBS, the use of non-price criteria is able to form reinforcing feedback loops that increase the competitiveness of the non-opportunistic and competent contractors. Some useful criteria should include contractors' past performance, financial capability, work experience, quality of key personnel and technical proposals. It should be noted here that the inclusion of the contractor's past performance has exceptional usefulness in reducing a contractor's willingness to sacrifice project quality and raise claims. Since contractors' BCR seeking behavior (including cutting corners and raising claims) will negatively affect their performance records, contractors are forced to trade off the benefit from BCR and its damages on their bidding competitiveness. To make these loops more effective, the owners need an objective and sensitive performance rating system. Several investigators are working on this line of research, such as the contractor's performance prediction, the contractor's quality performance assessing model, the quality-based contractor rating model and the multi-attribute evaluation of contractors [54-59].

\section{Scenario Analysis and Policy Evaluation}

\subsection{The Simulation Model for Analyzing the Dynamics of Market Competition}

In this section, the systems model of contractors' competitive behavior is transformed into an SD simulation model to support virtual experiments on the dynamics of market competition and managerial policies under the price-based and qualification-based awarding systems. The simulation model developed in this paper is not used for predicting market prices and market efficiency. Instead, it focuses on explaining and analyzing how specific policy affects contractors' competitive behavior and consequently the market prices. Through iterative simulations, the cause-effect relationships between specific variables of research interest can be understood from a systemic viewpoint.

Previous studies have developed many models to explain contractors' pricing behavior under the PBS. Most of these models regarded contractors' pricing as an optimum decision with the consideration of "cost" and "market competition" factors [60]. In addition to these two factors, Lo et al. [34] proposed $\mathrm{BCR}$ as an important factor, which has to be considered for analyzing contractors' pricing behavior, and developed a contractor's pricing model for the PBS. As the price is not the only selection criterion in the 
QBS, Lo and Yan [24] have proposed a more comprehensive model with the considerations of "cost", "market competition", "BCR" and "contractor's qualification", and the prototype has been adopted as four "stock-flow" modeling structures in this paper.

With four representative stocks, the conceptual feedback structure of the proposed model is shown as Figure 3. First, from a market competition perspective, as the level of market competition increases, contractors will be forced to lower their bidding prices. The considerations have been modeled as the "MP (market price)" stock-flow structure. Second, from a cost perspective, the contractor's cost condition will determine the bottom line for pricing. The considerations have been modeled as the "cost" stock-flow structure. Third, from the BCR perspective, it is assumed that contractors may accidentally submit an unreasonable low price and then adopt some actions to make up their sacrifices through obtaining BCR. Once contractors have experienced obtaining BCR in the past, they tend to repeatedly cut corners and raise unreasonable claims to maximize profit, regardless of the reasonableness of the award price. Contractors' expectation of BCR will evolve from contractors' previous experiences and will affect the contractors' decisions in determining their bidding prices. The considerations have been modeled as the "RBCR (reference beyond-contractual reward)" stock-flow structure. Finally, from the perspective of the contractor's qualification, the "CQS (contractor's qualification score)" stock-flow structure has been modeled. The meaning of "CQS" represents the specific "contractor's qualification score" in the qualification-based award system, and "RQS" represents the "reference qualification score" as the competitor's level of qualification score. Since the QBS considers not only price, but also the level of a contractor's qualification, contractors with better qualifications could take the competitive advantage to elevate their bidding price. Although many criteria will be used to evaluate a contractor's qualification, the adoption of contractors' past performance specifically generates a feedback relationship between qualification and BCR. Once owners adopt contractor's past performance to evaluate a contractor's qualification, contractors' BCR seeking behavior will deliver negative effects on the qualification and let the contractor face the competitive disadvantage in the tender stage.

In this paper, sustainable development and energy savings can be considered as the results or benefits of a healthy system for project procurements and project-based market competition. Accordingly, we measured the dynamics of market price under different market competition mechanisms (project awarding systems) by the SD methodology and simulation-based scenario analysis. In addition to conventional economic studies that focused on market price, this study considers other variables (and operational variables) related to sustainable development issues, such as quality (price feasibility), opportunistic bidding behavior (degree of opportunism) and construction claims (beyond-contractual reward). In addition, this paper focuses on the evaluation of market competition and contractor's behavior specifically under PBS and QBS defined in the proposed model. All of the definitions of the model variables and specific assumptions in this paper are summarized as shown in the Appendix (Table A1). Note that there are other variables that can be influenced by different bidding strategies in different countries, leading to different competitive behaviors. 


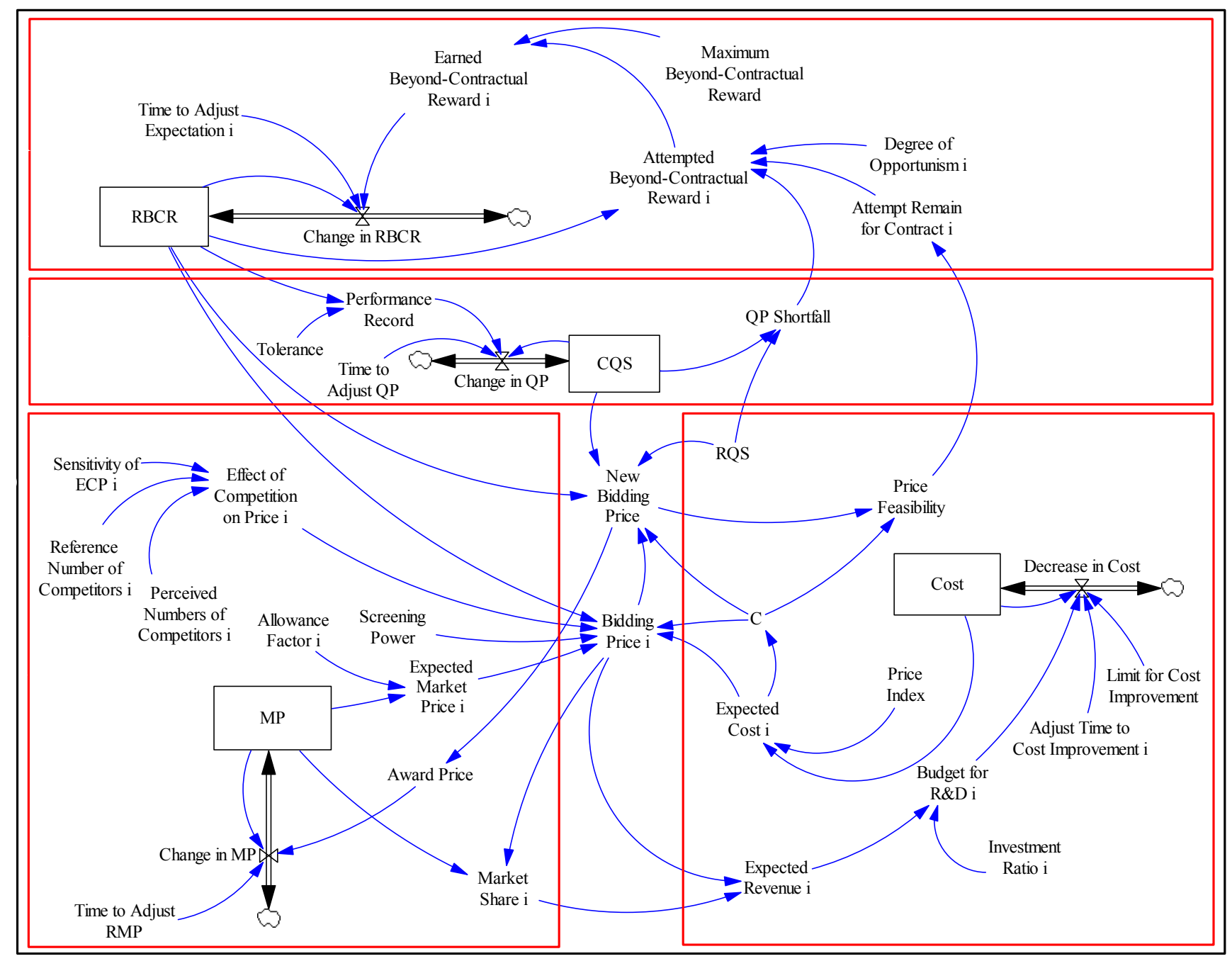

Figure 3. The conceptual framework of the simulation model. RBCR, reference beyond-contractual reward; CQS, contractor's qualification score; RQS, reference qualification score; MP, market price.

\subsection{Measuring the Market Efficiency and Policy Effectiveness}

In this section, a market efficiency index has been proposed to evaluate the effectiveness of different managerial policies along with the simulation results. In addition to the model from previous researchers, the paper proposes new elements of market efficiency and a measureable index. The proposed market efficiency index is different from market price, because it could facilitate the calculation of both the market performance over time and the accumulated results of changing market prices. The index would be more appropriate for policy evaluation and longitudinal analysis. By using the market efficiency index, this paper integrated the conceptual frameworks and simulation models from previous studies that can specifically conduct scenario analysis and evaluate the impacts of different management policies.

In order to explain the proposed market efficiency index, the concept of consumer surplus in microeconomic theory has to be briefly reviewed. The consumer surplus is the amount that consumers benefit by being able to purchase a product for a price that is less than the most that they would be willing to pay. It is a measure of the benefits that consumers gain from the consumption of goods and services. From the perspective of the consumer, a market is considered efficient when it provides the most 
consumer surplus as possible, while an inefficient market mechanism would induce the loss of consumer surplus. Accordingly, the measure can help researchers and policy makers to evaluate the impacts of different policies on the market performance.

Consumer surplus is the difference between the total amount that consumers are willing and able to pay for a good or service (indicated by the demand curve) and the total amount that they actually do pay (i.e., the market price for the product). The level of consumer surplus is shown by the area under the demand curve and above the ruling market price, as illustrated in Figure 4:

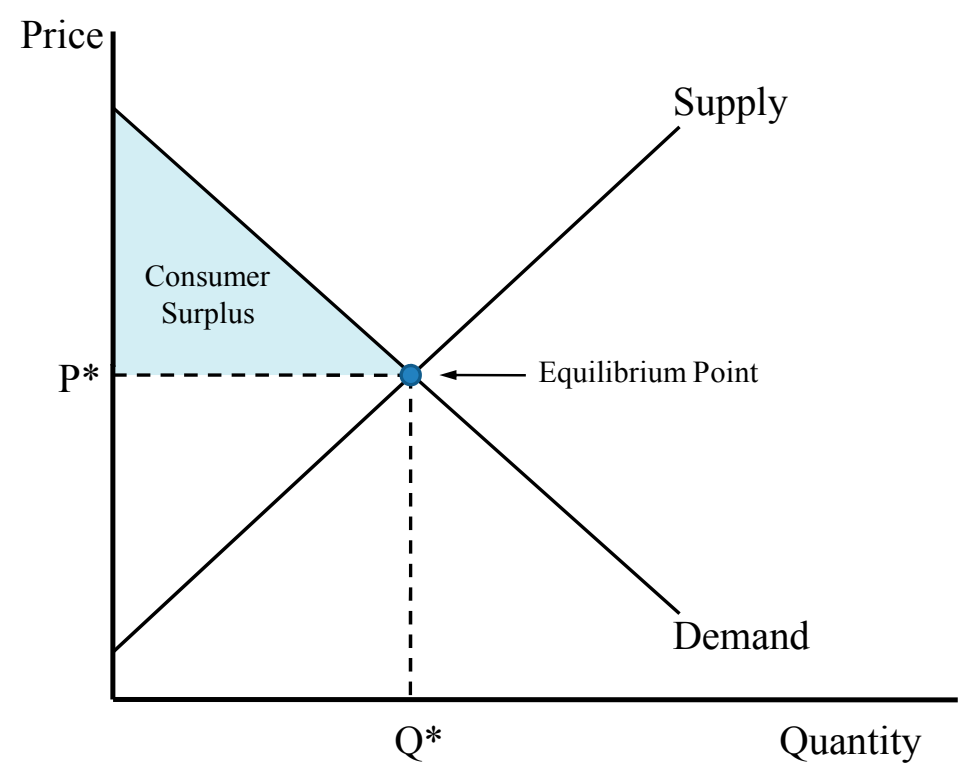

Figure 4. The conceptual model of equilibrium price and consumer surplus.

In the project-based awarding system, it is theoretically reasonable to infer that project owners would strive to award all projects at the equilibrium price level, which can maximize the consumer surplus, through a price competition mechanism. Since public project owners would have a fixed budget in a regular period, the demand line could be a vertical line, and the consumer surplus would be the difference between the budget $\left(\mathrm{B}_{\mathrm{x}}\right)$ and the total amount that they actually do pay (shown as Figure 5). From the project owners' viewpoint, the market is considered more efficient if the award price $\left(\mathrm{B}_{\mathrm{pi}}\right)$ is closer to the equilibrium price $\left(\mathrm{B}_{\mathrm{p}}^{*}\right)$. An example of an inefficient market is shown in Figure 6; a certain loss of consumer surplus will be induced if the award price is higher than the equilibrium price. Another inefficient case happens when the award price is lower than the equilibrium price, as shown in Figure 7. In this case, a loss of consumer surplus will be induced, because some projects cannot be delivered legally at the abnormally low price. Although the abnormal price $\left(\mathrm{B}_{\mathrm{pi}}\right)$ seems to save money for the project owners at the contract award stage, the total amount is the potential BCR and, thus, cannot be considered as the consumer surplus.

Based on the understanding of consumer surplus and the cases in the project-based competition, this paper further introduces the dynamic perspective of the market price and market efficiency. 


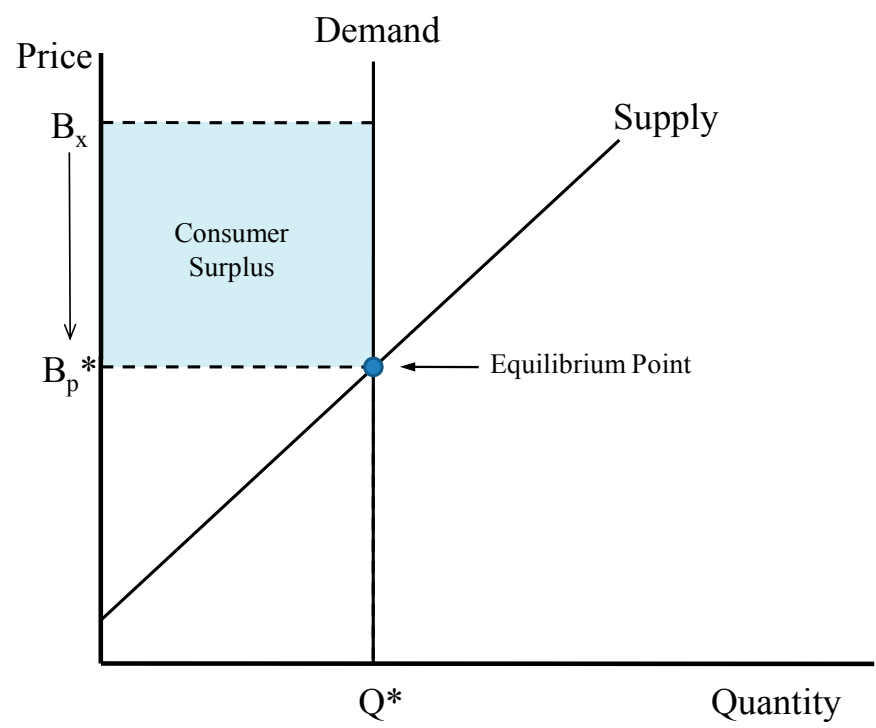

Figure 5. The conceptual model of consumer surplus in the project-based transaction.

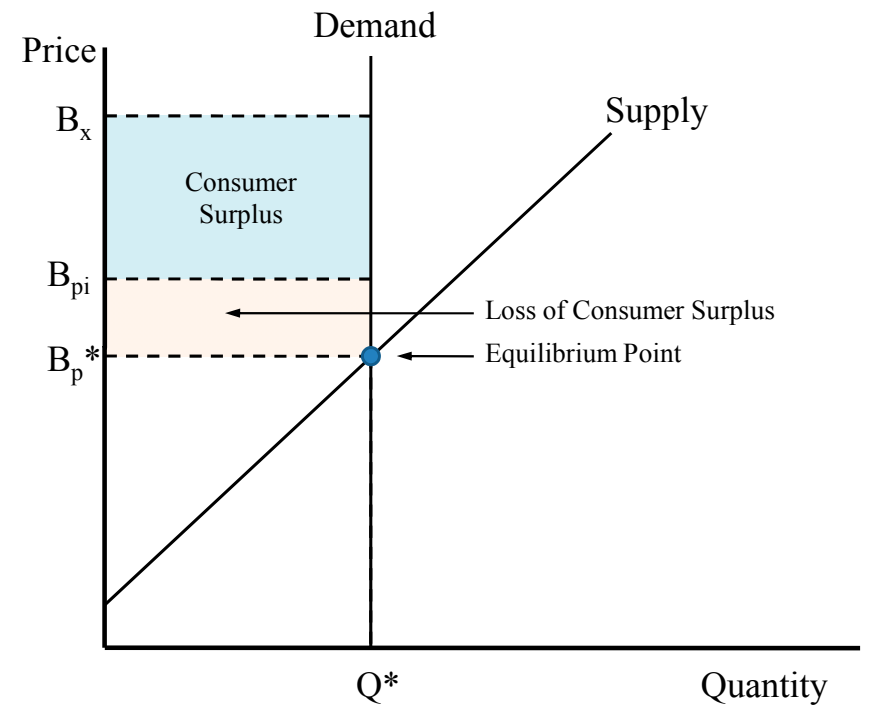

Figure 6. The loss of consumer surplus due to inefficient competition.

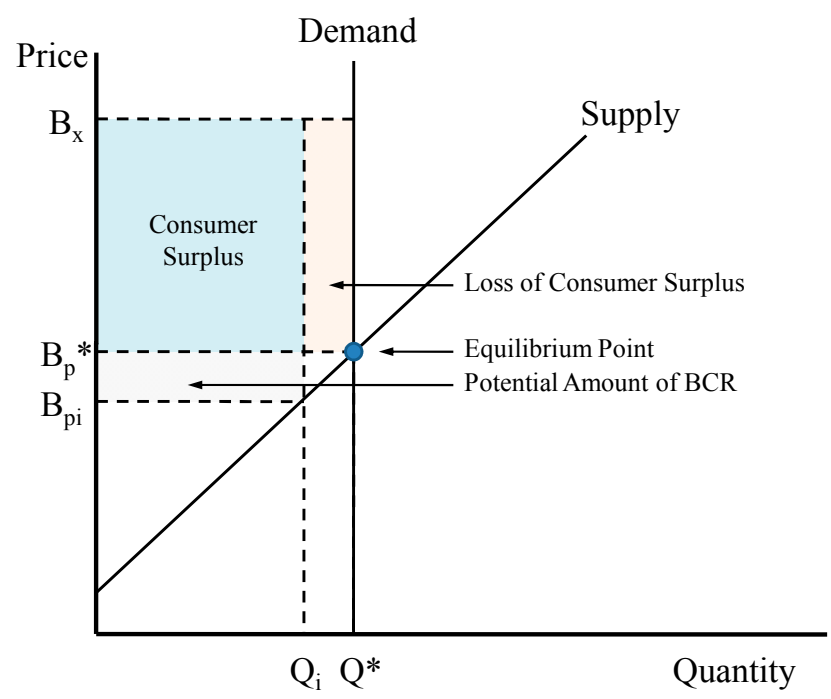

Figure 7. The loss of consumer surplus due to abnormally low bids. 
Previous studies have proposed that, under the project-based price competition mechanism, contractors sequentially bid for projects, and the market will gradually converge to the variable cost as the equilibrium market price [24,34]. Although the process of price convergence is dynamic, the market is more efficient as the process is faster and the accumulated difference between every award price and the equilibrium price is less. As shown in Figure 8, the loss of consumer surplus will be reduced, as well as the price competition mechanism functions efficiently. Accordingly, the degree of market efficiency (DME) can be measured as Equation (1):

$$
\mathrm{DME}=\frac{\sum_{i=1}^{n}\left(\mathrm{~B}_{\mathrm{x}}-\mathrm{B}_{\mathrm{pi}}\right)}{\left(\mathrm{B}_{\mathrm{x}}-\mathrm{B}_{\mathrm{p}}^{*}\right) \times N} \times 100 \%
$$

where $\mathrm{B}_{\mathrm{x}}$ represents the project budget, $\mathrm{B}_{\mathrm{pi}}$ represents the project award price, $\mathrm{B}_{\mathrm{p}}$ * represents the equilibrium market price and $N$ represents the number of projects awarded.

DME ranges from $0 \%-100 \%$. A higher DME value indicates that the market is more efficient for the project owners. DME $=100 \%$ implies that the market mechanism is perfectly efficient and the project owners can obtain maximum consumer surplus. DME $=0 \%$ implies that the market mechanism is completely inefficient and no consumer surplus is retained for the project owners.

The proposed DME measure can be flexibly applied to policy evaluation based on various time spaces. Thus, short- and long-range evaluation of managerial policies can be made with different settings of $N$ for the measure of DME.

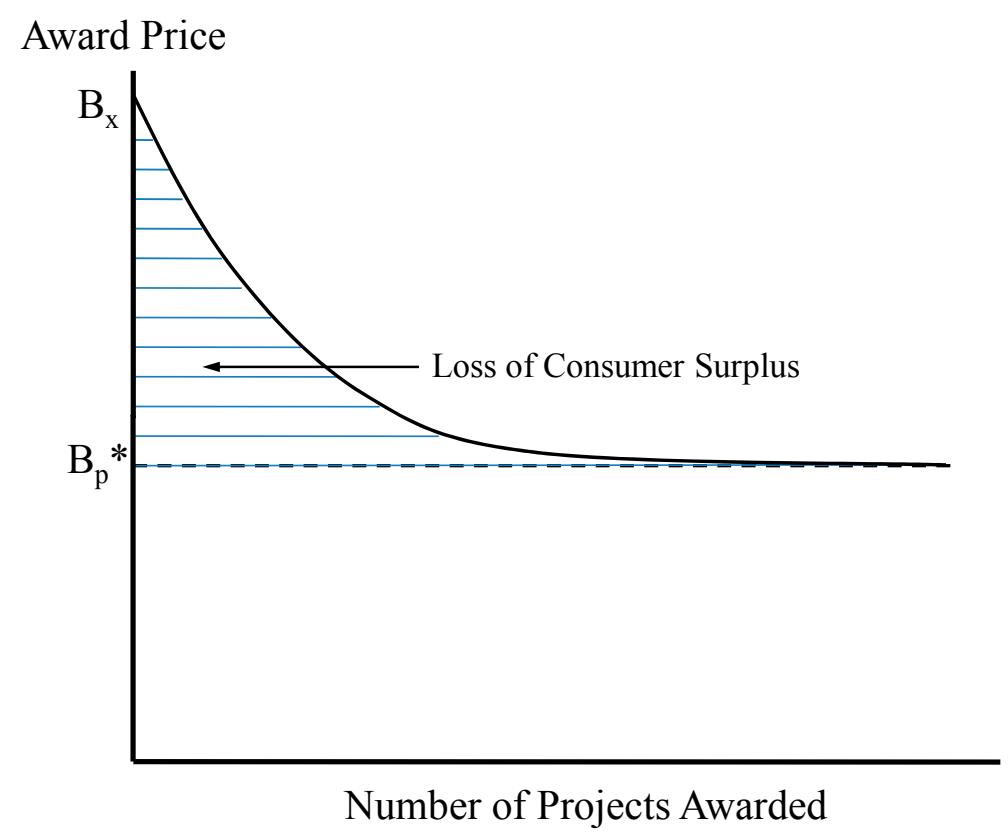

Figure 8. The dynamic perspective of consumer surplus.

Since the existence of BCR and abnormally low bids are the characteristics of the project-based market competition, Figure 9 is used to demonstrate the comprehensive view for the measurement of market efficiency. Once bidders submit abnormally low prices, BCRs are increased with time. Thus, the measure of market efficiency in the project-based competition should be modified as Equation (2): 


$$
\mathrm{DME}=\frac{\sum_{i=1}^{n}\left(\mathrm{~B}_{\mathrm{x}}-\mathrm{B}_{\mathrm{pi}}\right)-\sum_{i=1}^{n} \mathrm{BCR}_{\mathrm{i}}}{\left(\mathrm{B}_{\mathrm{x}}-\mathrm{B}_{\mathrm{p}}^{*}\right) \times N} \times 100 \%
$$

where $\sum_{i=1}^{n}\left(\mathrm{~B}_{\mathrm{x}}-\mathrm{B}_{\mathrm{pi}}\right)$ represents the accumulated cost saved from price competition during the period of projects awarded and $\sum_{i=1}^{n} \mathrm{BCR}_{\mathrm{i}}$ represents the accumulated amount of $\mathrm{BCR}$ in the period of projects awarded.

Market efficiency has been considered as a subtle concept that is hard to be tested by empirical studies [61]. The proposed measure of the degree of market efficiency is Equation (2), which can function as a comparative basis for simulation-based scenarios analysis and policy evaluation. The market efficiency, as well as the effectiveness of managerial policies for the project-based competition can thus be systematically evaluated.

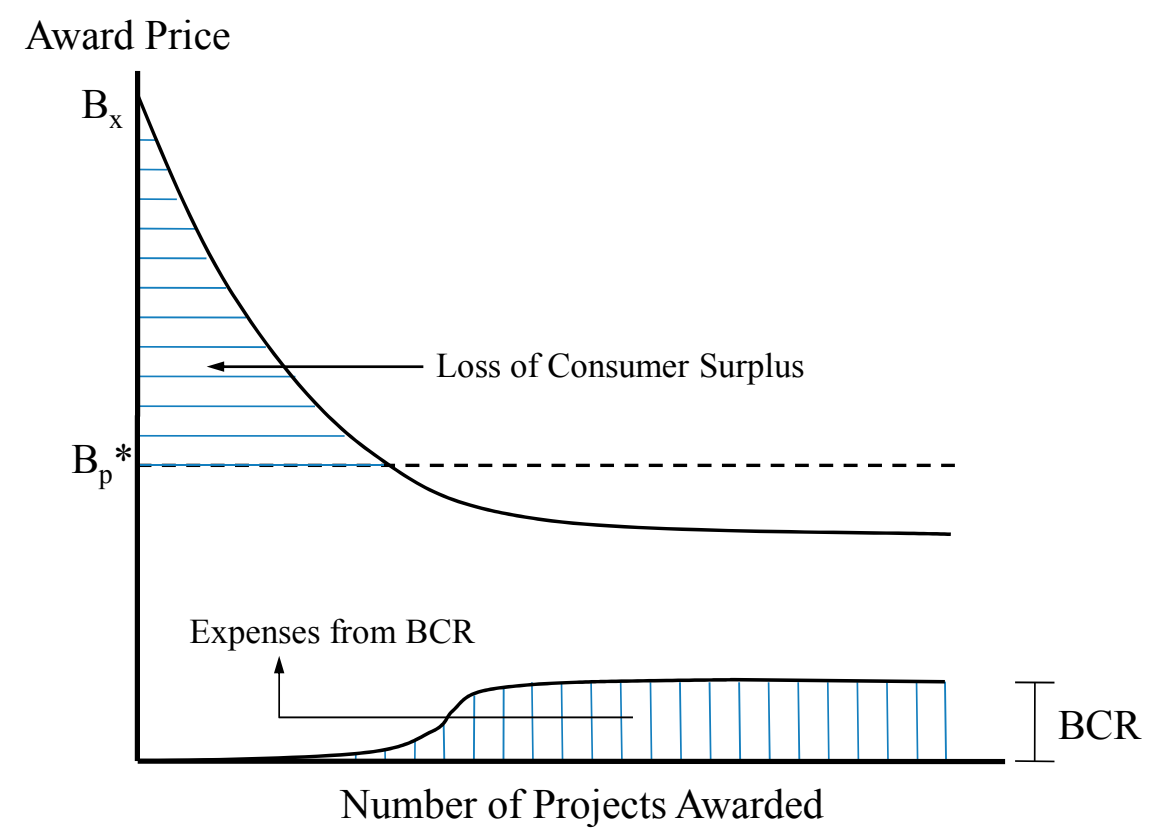

Figure 9. The comprehensive view for the measure of market efficiency.

\subsection{Policy Evaluation under the Price-based Awarding System}

This section simulates the market price trend for evaluating the effectiveness of managerial policies under the price-based awarding system. In cases without regard for BCR, the PBS assumes that the bidding prices of all contractors reflect their cost, and they abide by the contract and quality requirements. However, the results of the simulations reveal that, when excessive room for BCR exists in the market, contractors who apply an opportunistic bidding strategy enjoy a higher possibility to take extra market share. This will induce them to tender with even lower prices and then pursue compensation from BCR. Therefore, even when the market price is moving toward a certain equilibrium level with time, the market price turns out to be lower than the contractors' cost, forcing other contractors in the market to survive upon BCR. 
To improve the market efficiency, two managerial policies are tested in this section. The first policy evaluation is to test the effects of the market competition level on the market efficiency (Policy A). The second policy evaluation is to test the effects of the owner's project management system on the market efficiency (Policy B).

Scenario analysis is performed, and different scenarios under specific policies can be evaluated by the proposed DME measurement. For scenario analysis under Policy A, different numbers of competitors are separately controlled for simulating three distinctive market competition levels, moderate, very keen and very slack. In the proposed model, the reference number of competitors (RNC) assumed by contractors is seven; when the perceived number of competitors (PNC) exceeds seven, price competition among contractors becomes keener. Therefore, the input parameter for PNC was set as random variables, RANDOM (5-10), RANDOM (8-13) and RANDOM (3-6) to simulate the market price trends under three distinctive market competition levels. Although the simulation results suggest that the market prices reached under the three distinctive market competition levels can drop to a price level lower than the contractor's cost, the calculated DMEs demonstrate different consumer surpluses under different market competition levels. As shown in Figure 10, the very keen competition level can generate a relatively efficient market environment $(88.7 \%$ and $77.4 \%$ of total consumer surplus obtained for different time spaces), while the very slack competition environment can only generate $65.8 \%$ and $46.6 \%$ of total consumer surplus for the same time spaces (as shown in Table 1). Comparative degrees of market efficiency (CDME) to the most efficient policy (A2) can be further calculated for Policy A1 and Policy A3 (refer to Table 1). The CDMEs can help policy makers to evaluate the marginal effectiveness of controlling the number of competitors under the same policy direction.

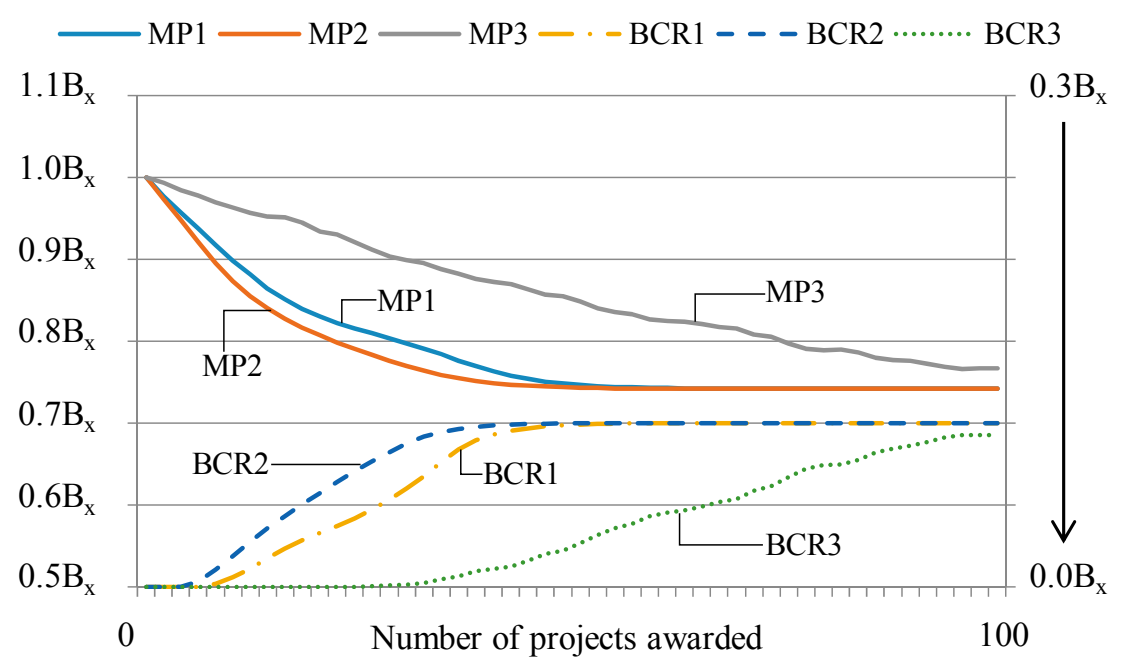

Figure 10. Simulated market prices under different market competition levels.

The paper further examines the importance of the owner's project management system as Policy B. The degree of strictness of the owner's project management system is assumed to affect the maximum amount of $\mathrm{BCR}(\mathrm{MBCR})$, where $\mathrm{MBCR}=0.1 \mathrm{~B}_{\mathrm{x}}$ represents that the maximum $\mathrm{BCR}$ is $10 \%$ of the owner's budget. The MBCR is separately set to simulate the market prices under three different degrees of strictness of the owner's project management systems (the MBCR is separately set as $0.1 \mathrm{~B}_{\mathrm{x}}, 0.06 \mathrm{~B}_{\mathrm{x}}$ and $0.02 \mathrm{~B}_{\mathrm{x}}$ ). The lower the MBCR is, the stricter the project management, and vice versa. The simulation result shows that, at the same competition level, different BCR levels result in different 
equilibriums of market price (see Figure 11). Therefore, the simulation results demonstrate that reducing the possibility and amount of BCR is the critical task for project owners.

Table 1. The numerical analysis of market efficiency under managerial Policy A. CDME, comparative degrees of market efficiency.

\begin{tabular}{ccccccc}
\hline Scenarios & \multicolumn{2}{c}{ Policy A1 } & \multicolumn{2}{c}{ Policy A2 } & \multicolumn{2}{c}{ Policy A3 } \\
\hline Time space & $\mathrm{N}=100$ & $\mathrm{~N}=50$ & $\mathrm{~N}=100$ & $\mathrm{~N}=50$ & $\mathrm{~N}=100$ & $\mathrm{~N}=50$ \\
$\sum_{i=1}^{n}\left(\mathrm{~B}_{\mathrm{x}}-\mathrm{B}_{\mathrm{pi}}\right)$ & $10.55 \mathrm{~B}_{\mathrm{x}}$ & $4.109 \mathrm{~B}_{\mathrm{x}}$ & $11.03 \mathrm{~B}_{\mathrm{x}}$ & $4.569 \mathrm{~B}_{\mathrm{x}}$ & $6.935 \mathrm{~B}_{\mathrm{x}}$ & $1.954 \mathrm{~B}_{\mathrm{x}}$ \\
$\sum_{i=1}^{n} \mathrm{BCR}_{\mathrm{i}}$ & & & & & & \\
$\mathrm{DME}$ & $3.655 \mathrm{~B}_{\mathrm{x}}$ & $1.157 \mathrm{~B}_{\mathrm{x}}$ & $3.999 \mathrm{~B}_{\mathrm{x}}$ & $1.501 \mathrm{~B}_{\mathrm{x}}$ & $1.721 \mathrm{~B}_{\mathrm{x}}$ & $0.106 \mathrm{~B}_{\mathrm{x}}$ \\
$\mathrm{CDME}$ & $87.1 \%$ & $74.0 \%$ & $88.7 \%$ & $77.4 \%$ & $65.8 \%$ & $46.6 \%$ \\
\hline
\end{tabular}

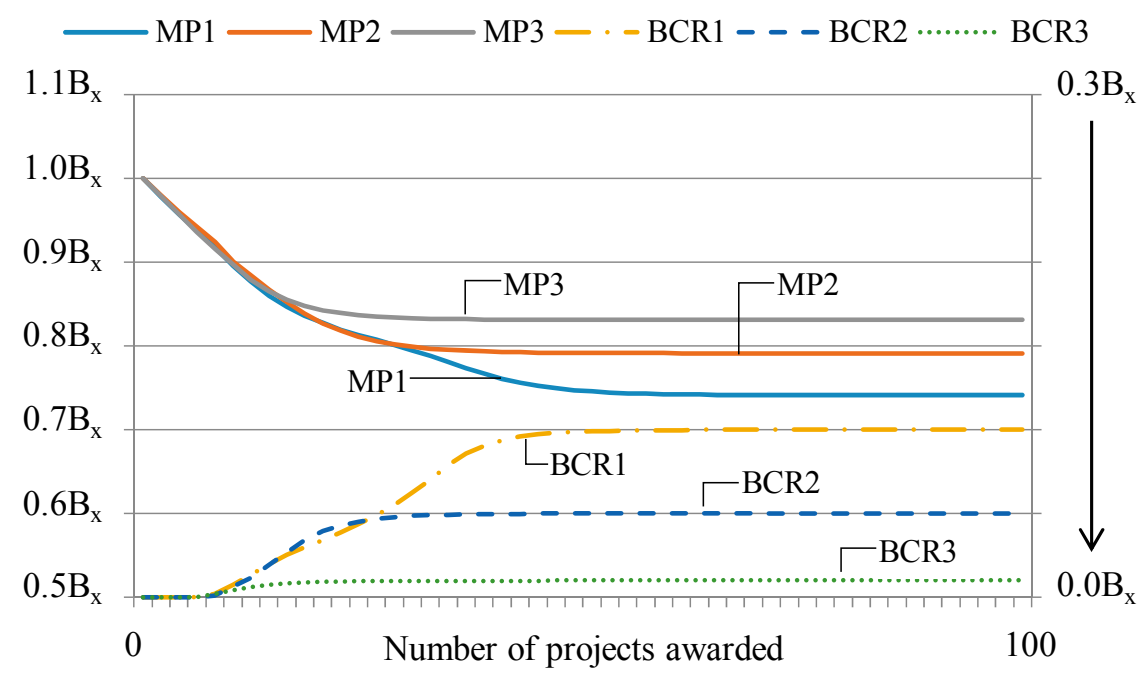

Figure 11. Simulated market prices under different project management systems.

DMEs under different strictness of the project management system are evaluated to improve the understanding of the effectiveness of the policy. As shown in Table 2, the calculated DMEs suggest that, under the same competition level, market efficiency can be improved by Policy B (from $87.2 \%-90 \%$ of total consumer surplus for 100 projects awarded; from $74.7 \%-80 \%$ of total consumer surplus for a 50 projects awarded time space). CDMEs are calculated to understand the marginal effectiveness of the efforts on strengthening the project management system as the reference for decision making.

Table 2. The numerical analysis of market efficiency under managerial Policy B.

\begin{tabular}{ccccccc}
\hline Scenarios & \multicolumn{2}{c}{ Policy B1 } & \multicolumn{2}{c}{ Policy B2 } & \multicolumn{2}{c}{ Policy B3 } \\
\hline Time space & $\mathrm{N}=100$ & $\mathrm{~N}=50$ & $\mathrm{~N}=100$ & $\mathrm{~N}=50$ & $\mathrm{~N}=100$ & $\mathrm{~N}=50$ \\
$\sum_{i=1}^{n}\left(\mathrm{~B}_{\mathrm{x}}-\mathrm{B}_{\mathrm{pi}}\right)$ & $10.60 \mathrm{~B}_{\mathrm{x}}$ & $4.150 \mathrm{~B}_{\mathrm{x}}$ & $9.055 \mathrm{~B}_{\mathrm{x}}$ & $3.844 \mathrm{~B}_{\mathrm{x}}$ & $7.568 \mathrm{~B}_{\mathrm{x}}$ & $3.356 \mathrm{~B}_{\mathrm{x}}$ \\
$\sum_{i=1}^{n} \mathrm{BCR}_{\mathrm{i}}$ & & & & & & \\
$\mathrm{DME}$ & $3.688 \mathrm{~B}_{\mathrm{x}}$ & $1.191 \mathrm{~B}_{\mathrm{x}}$ & $2.067 \mathrm{~B}_{\mathrm{x}}$ & $0.817 \mathrm{~B}_{\mathrm{x}}$ & $0.434 \mathrm{~B}_{\mathrm{x}}$ & $0.184 \mathrm{~B}_{\mathrm{x}}$ \\
$\mathrm{CDME}$ & $87.2 \%$ & $74.7 \%$ & $88.2 \%$ & $76.4 \%$ & $90.0 \%$ & $80.0 \%$ \\
\hline
\end{tabular}




\subsection{Policy Evaluation under the Qualification-Based Awarding System}

This section tests the market competitive behavior and market efficiency under the QBS. Two managerial policies are evaluated with scenario analysis. The first policy evaluation is to understand the effects of the owner's qualification standards on the market efficiency (Policy C). The second policy evaluation is to understand the effects of the owner's performance rating system on the market efficiency (Policy D).

For the evaluation of Policy $\mathrm{C}$, the owner's qualification standard is associated with the competition environment. Three scenarios are analyzed by assuming: (1) that a contractor dominates the market; (2) a very keen competition; and (3) a fairly dynamic competition environment (a contractor's qualification score is significantly higher than the reference qualification score in the market; is significantly lower than the reference qualification score; is slightly lower than the reference qualification score, respectively). The simulation results suggest that, once a contractor dominates the market, the contractor can gradually increase the bid price with a relatively competitive advantage, and thus, the market price increased over time (refer to MP1 in Figure 12). On the contrary, when most of the contractors' qualifications are worse than the general level of the competitors' qualification, contractors are forced to cut the price for their relative disadvantage in qualification. Thus, the price competition pressure forces the market price to be lower than the contractor's cost, and the contractor will be forced to obtain BCR to make up the sacrifice (refer to MP2 in Figure 12). MP3 in Figure 10 represents the dynamic market price trend when the market is fairly competitive and no dominant contractor exists.

The DME measurements demonstrate the significant difference of different qualification standards. For scenarios analysis under Policy $\mathrm{C}$, the DME of the market dominated by a contractor would only reach $3.9 \%$ and $8.1 \%$ of total consumer surplus for a 100 time space and a 50 time space, respectively, while proper competition can reach $97.2 \%$ and $94.3 \%$ of total consumer surplus, respectively (refer to Table 3). The CDMEs can further help policy makers to evaluate the marginal effectiveness of controlling qualification standards under the same policy direction.

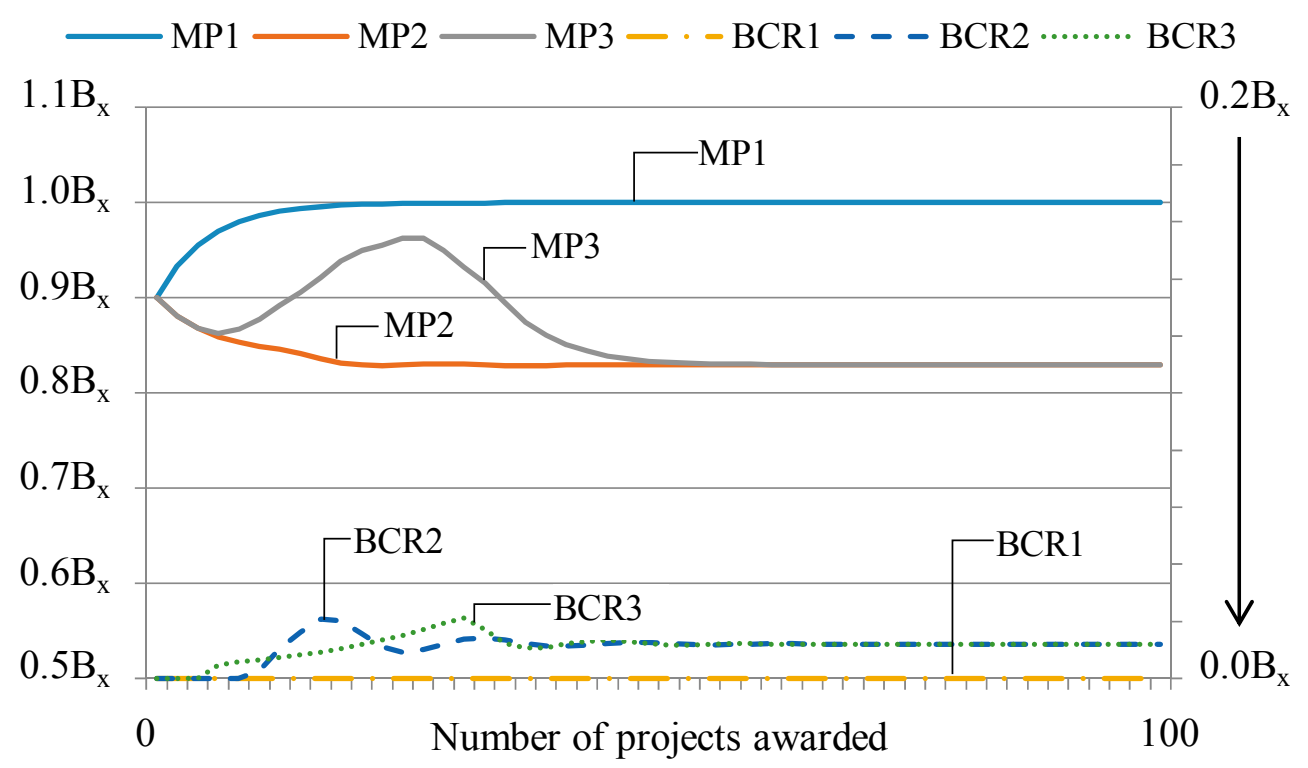

Figure 12. Simulated market prices under different qualification standards. 
Table 3. The numerical analysis of market efficiency under managerial Policy C.

\begin{tabular}{ccccccc}
\hline Scenarios & \multicolumn{2}{c}{ Policy C1 } & \multicolumn{2}{c}{ Policy C2 } & \multicolumn{2}{c}{ Policy C3 } \\
\hline $\begin{array}{c}\text { Time space } \\
\sum_{i=1}^{n}\left(\mathrm{~B}_{\mathrm{x}}-\mathrm{B}_{\mathrm{pi}}\right)\end{array}$ & $\mathrm{N}=100$ & $\mathrm{~N}=50$ & $\mathrm{~N}=100$ & $\mathrm{~N}=50$ & $\mathrm{~N}=100$ & $\mathrm{~N}=50$ \\
$\sum_{i=1}^{n} \mathrm{BCR}_{\mathrm{i}}$ & $0.303 \mathrm{~B}_{\mathrm{x}}$ & $0.303 \mathrm{~B}_{\mathrm{x}}$ & $8.256 \mathrm{~B}_{\mathrm{x}}$ & $3.991 \mathrm{~B}_{\mathrm{x}}$ & $6.877 \mathrm{~B}_{\mathrm{x}}$ & $2.623 \mathrm{~B}_{\mathrm{x}}$ \\
$\mathrm{DME}$ & & & & & & \\
$\mathrm{CDME}$ & $3.0 \mathrm{~B}_{\mathrm{x}}$ & $0.0 \mathrm{~B}_{\mathrm{x}}$ & $0.556 \mathrm{~B}_{\mathrm{x}}$ & $0.255 \mathrm{~B}_{\mathrm{x}}$ & $0.567 \mathrm{~B}_{\mathrm{x}}$ & $0.266 \mathrm{~B}_{\mathrm{x}}$ \\
\hline
\end{tabular}

The evaluation of Policy D examines the effects of the owner's quality consciousness on market efficiency. This paper uses different settings of owner's tolerance of defects to represent different levels of owner's quality consciousness. As the owner's quality consciousness is higher, the owner's tolerance of defects is lower, and contractor's work performance will be more strictly rated in the qualification score. The owner's tolerance of defects has been divided into three levels for policy evaluation $\left(0.05 \mathrm{~B}_{\mathrm{x}}\right.$, $0.01 \mathrm{~B}_{\mathrm{x}}, 0.1 \mathrm{~B}_{\mathrm{x}}$, respectively).

Figure 13 shows the impacts of the low tolerance of defects on the market efficiency. As the owner's tolerance of defects is lower, contractors' expected BCR decreases, and the competitive price would be closer to the contractor's cost. The simulation results suggest that, once owners keep high quality consciousness with a low tolerance of defects and rate contractors' performances strictly, contractors' intentions to BCR can be effectively controlled and contractors' bidding price can be directed to a reasonable level. For the dynamics of competition, DMEs reflect the significant effects of Policy D (shown in Table 4). For example, once the owner implements a strict performance rating policy, the market efficiency is $97.7 \%$ and $95.3 \%$ of total consumer surplus based on 100 and 50 time spaces, respectively, but can fall to $65 \%$ and $32.1 \%$ of total consumer surplus in the same time if the owner did not strictly conduct a performance rating system. The cumulated amount of BCR also reflects the effectiveness of Policy D.

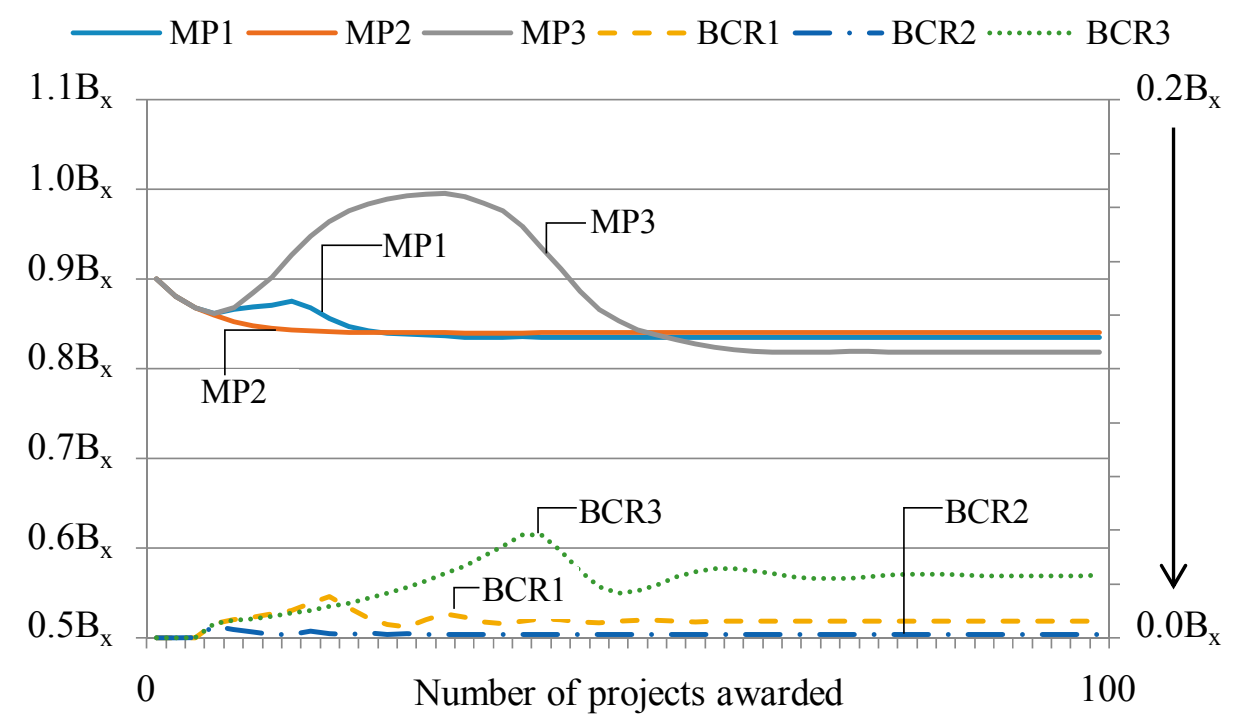

Figure 13. Simulated market prices when contractor's past performance is included as the main project awarding criterion. 
Table 4. The numerical analysis of market efficiency under managerial Policy D.

\begin{tabular}{ccccccc}
\hline Scenarios & \multicolumn{2}{c}{ Policy D1 } & \multicolumn{2}{c}{ Policy D2 } & \multicolumn{2}{c}{ Policy D3 } \\
\hline Time space & $\mathrm{N}=100$ & $\mathrm{~N}=50$ & $\mathrm{~N}=100$ & $\mathrm{~N}=50$ & $\mathrm{~N}=100$ & $\mathrm{~N}=50$ \\
$\sum_{i=1}^{n}\left(\mathrm{~B}_{\mathrm{x}}-\mathrm{B}_{\mathrm{pi}}\right)$ & $7.841 \mathrm{~B}_{\mathrm{x}}$ & $3.724 \mathrm{~B}_{\mathrm{x}}$ & $7.807 \mathrm{~B}_{\mathrm{x}}$ & $3.813 \mathrm{~B}_{\mathrm{x}}$ & $6.156 \mathrm{~B}_{\mathrm{x}}$ & $1.697 \mathrm{~B}_{\mathrm{x}}$ \\
$\sum_{i=1}^{n} \mathrm{BCR}_{\mathrm{i}}$ & $0.322 \mathrm{~B}_{\mathrm{x}}$ & $0.167 \mathrm{~B}_{\mathrm{x}}$ & $0.068 \mathrm{~B}_{\mathrm{x}}$ & $0.037 \mathrm{~B}_{\mathrm{x}}$ & $1.002 \mathrm{~B}_{\mathrm{x}}$ & $0.427 \mathrm{~B}_{\mathrm{x}}$ \\
$\mathrm{DME}$ & $94.9 \%$ & $89.8 \%$ & $97.7 \%$ & $95.3 \%$ & $65.0 \%$ & $32.1 \%$ \\
$\mathrm{CDME}$ & $97.2 \%$ & $94.2 \%$ & $100 \%$ & $100 \%$ & $66.6 \%$ & $33.6 \%$ \\
\hline
\end{tabular}

\section{Conclusions}

While awareness and new standards for sustainability are increasingly accepted in developed countries, effective governmental policies and market mechanisms could be strong facilitators that promote the quality of living and green innovation. Sustainable development and energy savings therefore are the benefits evolving from a healthy system of project procurement and market competition. From a systems perspective, this paper identified the characteristics of the project-based market competition and contractor's behavioral feedback loops induced in the building and construction sectors to better understand the system and policies for improving industry performance. The proposed system dynamics model took an across-projects viewpoint to analyze the persistent relationships between project awarding systems and contractors' competitive behavior as a whole system issue. Instead of showing how a project awarding system induces a project outcome, this study focused on discovering contractors' competitive behavioral loops under specific market environments. By understanding the whole system of the contractors' behavior, the dynamics of market competition and policy implications for sustainable developments can thus be systematically analyzed. This paper proposes the perspective of market efficiency and a measureable index that helps to calculate the market performance over time and the accumulated results of changing market prices. Compared to the conventional approach focused on market equilibrium price, this paper contributes to quantifying the impacts of intended policies and objectively evaluates the performance over time with scenarios analysis performed by iterative simulations.

Based on the research results, four policy implications were identified for facilitating sustainable development in the building and construction sectors, with an improved project-based market competition mechanism. First, when BCR becomes one of the inherent factors in the project-based market competition mechanism, the level of competition is related to market efficiency, but has less impact on the equilibrium market price level. Governmental policy on qualifying contractors and controlling the number of competitors would significantly improve consumer surplus, while abnormal bids could still be a concern in the system. Second, contractors' expectation of BCR is a source of opportunistic bidding behavior directly related to the strictness of the owner's contractual and operational project management system. As the project management system is improving, the market price level would be evolved to a reasonable equilibrium point sooner and higher consumer surplus obtained. The findings suggest some policy leverage on the improvements of project quality control and management system, contractual arrangements for disputes and claims management and other institutional arrangements to lower contractor's expectation of BCR. Third, the use of non-price criteria for project awarding, such as 
contractors' past performance, work experience, financial capability, quality of key personnel and technical proposals, would enhance the positive feedback effects that increase the competitiveness of the non-opportunistic and competent contractors. Our simulation-based scenario analysis demonstrated that the qualification standards have significant impacts on contractors' relative competitive advantages and the market efficiency. Finally, the simulation results suggest that the owners' quality consciousness and rating system for contractors' performances are significant factors that moderate contractors' opportunistic bidding behavior, and the market price can be directed to a reasonable level. The results indicate the importance of the weight of past performance in the qualification-based evaluation process, so as to enlarge the competitive advantage of contractors who provide higher quality products and reduce the adverse effects of abnormally low bids.

Methodologically, this paper has built up an analytical framework and operational models for analyzing the project-based competitive market and policy implications for sustainable developments. This can practically help policy makers to pursue more consumer surpluses, as well as savings of project expense. Future research could adopt the proposed model for a specific project market and conduct an empirical study with real data. Note that there are other types of projects not included in the proposed model, such as collaborative project arrangements, contractor-owner partnering contracts and strategic alliance projects. Once the contractors' behavioral tendency, variables and model assumptions have been formalized, they can be applied or further modified to provide more valuable insights into project-based market competition and sustainable development.

\section{Acknowledgments}

This research was conducted with the grants from the Ministry of Science and Technology in Taiwan and the supportive resources for visiting research at Northwestern University, USA. The author would also like to thank the professional editors and reviewers for their valuable comments and suggestions.

\section{Conflicts of Interest}

The author declares no conflict of interest.

\section{Appendix}

The Appendix comprises the definitions and assumptions of the model variables adopted in this paper. Interested readers and researchers are welcome to contact the author for more details, and the model will be gladly shared.

Table A1. Definitions of model variables.

\begin{tabular}{cl}
\hline Model Variables & Definitions \\
\hline Bidding Price & Contractor's bidding price in the price-based awarding system. \\
\hline New Bidding Price & Contractor's bidding price in the qualification-based awarding system. \\
\hline & 1.The "MP" stock-flow structure \\
\hline MP & Market price. \\
\hline Change in MP & The increase or decrease of market price per time unit. \\
\hline
\end{tabular}


Table A1. Cont.

\begin{tabular}{|c|c|}
\hline Model Variables & Definitions \\
\hline \multicolumn{2}{|r|}{ 1.The "MP" stock-flow structure } \\
\hline Time to Adjust RMP & $\begin{array}{l}\text { Represents how quickly the contractor tries to correct the shortfall between MP and } \\
\text { actual award price: if the contractor seeks to correct the shortfall quickly, the adjustment } \\
\text { time would be small. }\end{array}$ \\
\hline Expected Market Price & $\begin{array}{l}\text { Since MP is considered as a reference to competitors' prices, it is reasonable to infer that } \\
\text { contractors will determine a price lower than MP, so as to win the bid. The adjusted price } \\
\text { is called "expected market price". }\end{array}$ \\
\hline Award Price & The lowest price among all the offers. \\
\hline Market Share & Market share. \\
\hline Allowance Factor & $\begin{array}{l}\text { Represents the discount rate on the market price. A higher discount rate indicates the } \\
\text { contractor is more eager to win the bid. }\end{array}$ \\
\hline Screening Power & The level of standards for contractor's pre-qualification. \\
\hline $\begin{array}{l}\text { Effect of Competition } \\
\text { on Price }\end{array}$ & $\begin{array}{l}\text { The parameter to indicate the effect of number of competitors on contractors' } \\
\text { bidding price. }\end{array}$ \\
\hline Sensitivity of ECP & $\begin{array}{l}\text { Sensitivity of ECP (SECP) represents the weight of the effect of competition on price, } \\
\text { where the value of SECP ranges from } 0-1 \text {. }\end{array}$ \\
\hline $\begin{array}{c}\text { Reference Number } \\
\text { of Competitors }\end{array}$ & $\begin{array}{l}\text { The predicted number of competitors based on previous bids (for example, } \\
\text { the average number of competitors in previous projects). }\end{array}$ \\
\hline $\begin{array}{l}\text { Perceived Number } \\
\text { of Competitors }\end{array}$ & The number of competitors speculated before the bid. \\
\hline \multicolumn{2}{|r|}{ 2.The "Cost" stock-flow structure } \\
\hline Cost & Contractor's cost. \\
\hline Decrease in Cost & The decrease or increase of contractor's cost per time unit. \\
\hline Limit for Cost Improvement & The upper limit of contractor's cost improvement. \\
\hline $\begin{array}{l}\text { Adjust Time to Cost } \\
\text { Improvement }\end{array}$ & The time needed for contractors to improve their cost advantage. \\
\hline Budget for R\&D & The budget for research and development. \\
\hline Investment Ratio & The investment ratio for cost improvement. \\
\hline Expected Cost & Contractor's expected cost. \\
\hline $\mathrm{C}$ & The contractor's cost condition will determine the bottom line for pricing. \\
\hline Price Feasibility & Price feasibility $=$ bidding price $/$ cost \\
\hline \multicolumn{2}{|r|}{ 3.The "BCR" stock-flow structure } \\
\hline RBCR & $\begin{array}{l}\text { The reference amount of beyond-contractual reward. It represents a contractor's } \\
\text { expectation of the possible amount of the BCR in a project. As contractors may have } \\
\text { different experiences of obtaining a BCR, each individual contractor is assumed to have } \\
\text { a different RBCR. }\end{array}$ \\
\hline Change in RBCR & The increase or decrease of RBCR per time unit. \\
\hline Time to Adjust Expectation & The time needed for contractors to adjust their RBCR. \\
\hline $\begin{array}{c}\text { Earned } \\
\text { Beyond-Contractual Reward }\end{array}$ & Represents the "earned beyond-contractual reward" in the latest project. \\
\hline $\begin{array}{c}\text { Maximum } \\
\text { Beyond-Contractual Reward } \\
\end{array}$ & Represents the maximum beyond-contractual reward. \\
\hline $\begin{array}{c}\text { Attempted } \\
\text { Beyond-Contractual Reward } \\
\end{array}$ & Represents the attempted beyond-contractual reward. \\
\hline
\end{tabular}


Table A1. Cont.

\begin{tabular}{|c|c|}
\hline Model Variables & Definitions \\
\hline \multicolumn{2}{|r|}{ 3.The "BCR" stock-flow structure } \\
\hline Degree of Opportunism & $\begin{array}{l}\text { Degree of Opportunism ranges between } 0 \text { and } 1 \text { in this study, and the higher it is, the } \\
\text { stronger the tendency for the contractor to indulge in abnormal behaviors for RBCR. }\end{array}$ \\
\hline $\begin{array}{l}\text { Attempt Remain } \\
\text { for Contract }\end{array}$ & Represents the attempted beyond-contractual reward. \\
\hline \multicolumn{2}{|r|}{ 4.The "CQS" stock-flow structure } \\
\hline CQS & $\begin{array}{l}\text { Represents specific "contractor's qualification score" in the qualification-based } \\
\text { award system. }\end{array}$ \\
\hline Change in QP & The increase or decrease of qualification score per time unit. \\
\hline Time to Adjust QP & The time needed for contractors to adjust their qualification. \\
\hline RQS & Represents "reference qualification score" as the competitor's level of qualification score. \\
\hline Performance Record & The contractor's past performance be recorded from $0-100$. \\
\hline Tolerance & $\begin{array}{l}\text { The owner's tolerance of defects (measured by the BCR gained by the contractor). } \\
\text { The variable represents different levels of the owner's quality consciousness. As the } \\
\text { owner's quality consciousness is higher, the owner's tolerance of defects is lower and } \\
\text { contractor's work performance will be more strictly rated into qualification score. }\end{array}$ \\
\hline QP Shortfall & The gap between CQS and RQS. \\
\hline
\end{tabular}

\section{References}

1. Schilling, D.R. Global Construction Expected to Increase by $\$ 4.8$ Trillion by 2020. Available online: http://www.industrytap.com/global-construction-expected-to-increase-by-4-8-trillion-by2020/1483 (accessed on 2 March 2015).

2. Ding, G.K.C. Sustainable construction-The role of environmental assessment tools. J. Environ. Manag. 2008, 86, 451-464.

3. Hsueh, S.L.; Yan, M.R. A multimethodology contractor assessment model for facilitating green innovation: The view of energy and environmental protection. Sci. World J. 2013, doi:10.1155/2013/624340.

4. Lam, T.I.; Chan, H.W.; Poon, C.S.; Chau, C.K.; Chun, K.P. Factors affecting the implementation of green specifications in construction. J. Environ. Manag. 2010, 91, 654-661.

5. Spence, R.; Mulligan, H. Sustainable development and the construction industry. Habitat Int. 1995, 19, 279-292.

6. Ngowi, A.B. Creating competitive advantage by using environment-friendly building processes. Build. Environ. 2001, 36, 291-298.

7. Cole, R.J. Building environmental assessment methods: Clarifying intentions. Build. Res. Inf. 1999, 27, 230-246.

8. Holmes, J.; Hudson, G. An evaluation of the objectives of the BREEAM scheme for offices: A local case study. In Proceedings of the Cutting Edge 2000, Windsor, UK, 6-8 September 2000.

9. Johnson, S. Greener Buildings: Environmental Impact of Property; MacMillan: Basingstoke, UK, 1993.

10. Cole, R.J. Emerging trends in building environmental assessment methods. Build. Res. Inf. 1998, 26, 3-16. 
11. Crawley, D.; Aho, I. Building environmental assessment methods: Application and development trends. Build. Res. Inf. 1999, 27, 300-308.

12. Rees, W. The built environment and the ecosphere: A global perspective. Build. Res. Inf. 1999, 27, 206-220.

13. Blauert, J.; Zadek, S. Mediating Sustainability: Growing Policy from the Grassroots, 1st ed.; Kumarian Press: West Hartford, CT, USA, 1998; pp. 57-58.

14. Krigsvoll, G.; Fumo, M.; Morbiducci, R. National and international standardization relevant for sustainability in construction. Sustainability 2010, 2, 3777-3791.

15. Ahn, C.; Lee, S.H.; Pena-Mora, F.; Abourizk, S. Toward environmentally sustainable construction processes: The U.S. and Canada's perspective on energy consumption and GHG/CAP emissions. Sustainability 2010, 2, 354-370.

16. Bal, M.; Bryde, D.; Fearon, D.; Ochieng, E. Stakeholder engagement: Achieving sustainability in the construction sector. Sustainability 2013, 6, 695-710.

17. Pernick, R.; Wilder, C. The Clean Tech Revolution: The Next Big Growth and Investment Opportunity; HarperCollins: New York, NY, USA, 2007.

18. Toole, T.M. Uncertainty and home builders' adoption of technological innovations. J. Constr. Eng. Manag. 1998, 124, 323-332.

19. Kolk, A.; Pinkse, J. Stakeholder mismanagement and corporate social responsibility crises. Eur. Manag. J. 2006, 24, 59-72.

20. Arruda, L.R.; Lameira, V.J.; Quelhas, O.L.G.; Pereira, F.N. Sustainability in the Brazilian heavy construction industry: An analysis of organizational practices. Sustainability 2013, 5, 4312-4328.

21. Herbsman, Z.; Ellis, R. Multiparameter bidding system-innovation in contract administration. J. Constr. Eng. Manag. 1992, 118, 142-150.

22. Gransberg, D.D.; Ellicott, M.A. Best Value Contracting: Breaking the Low-Bid Paradigm. In Proceedings of the 40th Annual Meeting of AACE International, Vancouver, BC, Canada, 23-26 June 1996.

23. Lo, W.; Yan, M.R. Evaluating qualification-based selection system: A simulation approach. J. Constr. Eng. Manag. 2009, 135, 458-465.

24. Qiao, Y.; Cummings, G. The use of qualification-based selection in public procurement: A survey research. J. Public Procure. 2003, 3, 215-249.

25. Chasey, A.D.; de la Garza, J.M.; Drew, D.R. Using simulation to understand the impact of deferred maintenance. Comput.-Aided Civ. Infrastruct. Eng. 2002, 17, 269-279.

26. Rodrigues, A.; Bowers, J. The role of System Dynamics in project management. Int. J. Proj. Manag. 1996, 14, 213-220.

27. Rahimiyan, M.; Mashhadi, H.R. Evaluating the efficiency of divestiture policy in promoting competitiveness using an analytical method and agent-based computational economics. Energy Policy 2010, 38, 1588-1595.

28. Sterman, J. Business Dynamics: Systems Thinking and Modeling for a Complex World, HAR/CDR edition; McGraw-Hill Education: Columbus, OH, USA, 2000.

29. Sengupta, J.K. Quality and efficiency. Econ. Model. 2000, 17, 195-207. 
30. Yan, M.R.; Hsueh, S.L. Contractor Selection System Review: Price-Based Versus Qualification-Based Systems. In Proceedings of the 26th International Conference of System Dynamics Society, Athens, Greece, 20-24 July 2008.

31. Carlton, D.W.; Perloff, J.M. Modern Industrial Organization, 3rd ed.; Addison Wesley Longman, Inc.: Chicago, IL, USA, 2000.

32. Gruneberg, S.L.; Ive, G.J. The Economics of the Modern Construction Firm; Macmillan: Basingstoke, UK, 2000.

33. Hillebrandt, P.M. Economic Theory and the Construction Industry, 3rd ed.; Macmillan: Basingstoke, UK, 2000.

34. Lo, W.; Lin, C.L.; Yan, M.R. Contractor's opportunistic bidding behavior and equilibrium price level in construction market. J. Constr. Eng. Manag. 2007, 133, 409-416.

35. Yan, M.R. The Market Competitive Behavior in the Project-Based Industries. In Proceedings of the 27th International Conference of System Dynamics Society, Albuquerque, NM, USA, 26-30 July 2009.

36. Qin, Z.; Hua, F.; Tang, H. Stability analysis of construction between owners and contractors in the construction market. J. Asian Archit. Build. Eng. 2010, 9, 409-414.

37. Ye, K.; Shen, L.; Xia, B.; Li, B. Key attributes underpinning different markup decision between public and private projects: A China study. Int. J. Proj. Manag. 2014, 32, 461-472.

38. Mohamed, K.A.; Khoury, S.S.; Hafez, S.M. Contractor's decision for bid profit reduction within opportunistic bidding behavior of claims recovery. Int. J. Proj. Manag. 2011, 29, 93-107.

39. Gunduz, M.; Karacan, V. Damage to treasury: Abnormally low tenders in public construction works. J. Leg. Aff. Disput. Resolut. Eng. Constr. 2009, 1, 130-136.

40. Chaovalitwongse, W.A.; Wang, W.; Williams, T.P.; Chaovalitwongse, P. Data mining framework to optimize the bid selection policy for competitively bid highway construction projects. $J$. Constr. Eng. Manag. 2012, 138, 277-286.

41. D’Alpaos, C.; Moretto, M.; Valbonesi, P.; Vergalli, S. Time overruns as opportunistic behavior in public procurement. J. Econ. 2013, 110, 25-43.

42. Williamson, O.E. The Economic Institutions of Capitalism; Free Press: New York, NY, USA, 1985.

43. Rooke, J.; Seymour, D.; Fellows, R. Planning for claims: An ethnography of industry culture. Constr. Manag. Econ. 2004, 22, 655-662.

44. Minniti, A. Product market competition, R\&D composition and growth. Econ. Model. 2010, 27, 417-421.

45. Disney, R.; Haskel, J.; Heden, Y. Restructuring and productivity growth in UK manufacturing. Econ. J. 2003, 113, 666-694.

46. Blundell, R.; Griffith, R.; van Reenen, J. Market share, market value and innovation in a panel of british manufacturing firms. Rev. Econ. Stud. 1999, 66, 529-554.

47. Nickell, S.J. Competition and corporate performance. J. Political Econ. 1996, 107, 715-730.

48. Bucci, A.; Parello, C.P. Horizontal innovation-based growth and product market competition. Econ. Model. 2009, 26, 213-221.

49. Ye, K.; Li, B.; Shen, L. Key factors considered in compiling tender prices for China's public works projects. J. Manag. Eng. 2013, 29, 206-215.

50. Ahmed, J.; Gharaibeh, N.G.; Damnjanovic, I.D. Best value bid selection methods for performance-based roadway maintenance contracts. Transp. Res. Rec. 2012, 2292, 12-19. 
51. Beard, J.; Loukakis, M.C.; Wundram, E.C. Design-Build: Planning through Development; McGraw-Hill: New York, NY, USA, 2001.

52. Wardani, E.I.; Messner, I.; Horman, J. Comparing procurement methods for design-build projects. J. Constr. Eng. Manag. 2006, 132, 230-238.

53. Lo, W.; Yan, M.R. Effects of design-build delivery system on the construction industry: A market perspective. J. Constr. Procure. 2008, 14, 98-107.

54. Alarcon, L.F.; Mourgues, C. Performance modeling for project awarding. J. Manag. Eng. 2002, 18, 52-60.

55. Yasamis, F.; Arditi, D.; Mohammadi, J. Assessing contractor quality performance. Constr. Manag. Econ. 2002, 20, 211-223.

56. Minchin, R.E.; Gary, R.; Smith, M. Quality-based contractor rating model for qualification and bidding purposed. J. Manag. Eng. 2005, 21, 38-43.

57. Brauers, W.K.M.; Zavadskas, E.K.; Turskis, Z.; Vilutiene, T. Multi-objective contractor's ranking by applying the MOORA method. J. Bus. Econ. Manag. 2008, 9, 245-255.

58. Zavadskas, E.K.; Turskis, Z.; Tamosaitiene, J. Contractor selection of construction in a competitive environment. J. Bus. Econ. Manag. 2008, 9, 181-187.

59. Zavadskas, E.K.; Vilutiene, T.; Turskis, Z.; Tamosaitiene, J. Contractor selection for construction work by applying SAW-GAND TOPSIS Grey techniques. J. Bus. Econ. Manag. 2010, 11, 34-55.

60. Yan, M.R.; Lo, W.; Lin, C.L. Critical driving force for contractor's opportunistic bidding behavior in public works. In Proceedings of the First International Conference on Construction Engineering and Management, Seoul, Korea, 16-19 October 2005; Korean Institute of Construction Engineering and Management: Seoul, Korea; pp. 417-423.

61. Wang, Y.; Liu, L.; Gu, R.; Cao, J.; Wang, H. Analysis of market efficiency for the Shanghai stock market over time. Phys. A 2010, 389, 1635-1642.

(C) 2015 by the authors; licensee MDPI, Basel, Switzerland. This article is an open access article distributed under the terms and conditions of the Creative Commons Attribution license (http://creativecommons.org/licenses/by/4.0/). 